University of Nebraska - Lincoln

DigitalCommons@University of Nebraska - Lincoln

Gordon Gallup Publications

Research Papers in Physics and Astronomy

December 1954

\title{
A Special Case of the Hammett Equation
}

W.R. Gilkerson

University of Kansas, Lawrence

Gordon A. Gallup

UNL,ggallup1@unl.edu

M.M. Jones

University of Kansas, Lawrence

Follow this and additional works at: https://digitalcommons.unl.edu/physicsgallup

Part of the Physics Commons

Gilkerson, W.R.; Gallup, Gordon A.; and Jones, M.M., "A Special Case of the Hammett Equation" (1954). Gordon Gallup Publications. 34.

https://digitalcommons.unl.edu/physicsgallup/34

This Article is brought to you for free and open access by the Research Papers in Physics and Astronomy at DigitalCommons@University of Nebraska - Lincoln. It has been accepted for inclusion in Gordon Gallup Publications by an authorized administrator of DigitalCommons@University of Nebraska - Lincoln. 


\title{
A Special Case of the Hammett Equation
}

\author{
W. R. GILKERSON*, G. A. GALLUP*, and M. M. JONES†
}

University of Kansas, Lawrence

\section{Introduction}

The Hammett equation was first used for coordinating information on the kinetics of organic reactions by Hammett and Pfluger (1). It was later extended by Hammett (2) (3) (4) and is now extensively used in studies concerned with the effect of changes in structure of an organic compound on the kinetics of various reactions these compounds undergo. The Hammett equation is

$$
\log \frac{k}{k_{0}}=\sigma p
$$

where

$k=$ rate constant for a reaction of a substituted compound

$k_{0}=$ rate constant for the reaction of the unsubstituted compound

$\sigma=$ constant specific for the substituent

$p=$ constant specific for the reaction

Hammett has shown that it is necessary to restrict the use of this equation to series of reactions in which the entrophy of activation is constant if the constant $\sigma$ is to be relaled to the electrical effects of the substituent on the reaction. This can easily be shown to require that changes in the kinetic energy must be the same for the series of reactions studied (5).

One of the results of later work on the correlation of the kinetics of the reactions of certain types of organic compounds has been to show that the Hammett equation may be used to relate the rates of substituted and unsubstituted compounds even when there are marked changes in the entropies of activation in a series (6) (7) (8) (9) (10) (11). There are at least two explanations for this result which can be shown by a careful consideration of the Hammett equation and its relation to the Absolute Reaction Rate Theory.

Transactions of the Kansas Academy of Science, Vol. 57, No. 3, 1954.

* AEC Fellows

†duPont Fellow 


\section{Discussion}

The Absolute Reaction Rate Theory shows that the rate of a chemical reaction is of the form

$$
k=K \frac{K T}{h} e^{-\frac{\Delta F^{*}}{R T}}
$$

where

$k$ is the rate constant for the reaction

$\kappa$ is the transmission coefficient

$\mathrm{K}$ is Boltzmann's constant

$\mathrm{T}$ is the absolute temperature

$b$ is Planck's constant

$\Delta \mathrm{F}^{*}$ is the standard free energy of activation

$R$ is the gas constant

Fram equation II we can easily obtain an expression for the difference in logarithms of any two rates as:

$$
\log \frac{k_{1}}{k_{2}}=\frac{\Delta F_{2}^{*}-\Delta F_{1}^{*}}{R T}
$$

where the subscripts refer to the two reactions.

From thermodynamics we may write

$$
\Delta F^{*}=\Delta H^{*}-T \Delta S^{*}
$$

When this is introduced into equation III we get

$$
\begin{aligned}
& \text { (V) } \log \frac{k_{1}}{k_{2}}=\frac{\left(\Delta H_{2}^{*}-T \Delta S_{2}^{*}\right)-\left(\Delta H_{1}^{*}-T \Delta S_{1}^{*}\right)}{R T} \\
& \text { (VI) } \log \frac{k_{1}}{k_{2}}=\frac{\Delta H_{2}^{*}-\Delta H_{1}^{*}}{R T}-\frac{\Delta S_{2}^{*}-\Delta S_{1}^{*}}{R}
\end{aligned}
$$

If, for the moment, we ignore the restriction of Hammett's equation to series of reactions where $\Delta S_{1} *=\Delta S_{2}{ }^{*}$ we may combine equations $\mathrm{VI}$ and I and write

(VII)

$$
\sigma \rho=\frac{\Delta H_{2}^{*}-\Delta H_{1}^{*}}{R T}-\frac{\Delta S_{2}^{*}-\Delta S_{1}^{*}}{R}
$$

It should be remembered that this is essentially the implicit assumption in the work which fits Hammett's equation to a series of reactions in which $\Delta S_{1} * \ldots \Delta S_{2} *$. There are two situations in which the Hammett 
equation will fit data on reactions of this type. These two cases will be discussed in turn.

I. Reactions in which

(VIII)

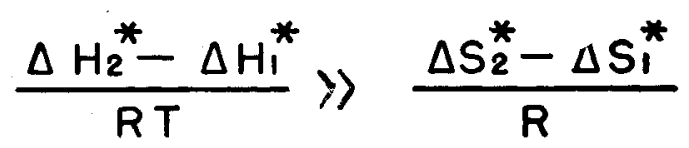

In reactions of this type the differences in the enthalpies of activation are sufficient to mask any effect of the differences in entropies. A numerical example of such a reaction is easily given. The figures given are typical. If the change in the heat of activation is 5000 cals and the entropy change is cal deg mole (Setting $\mathrm{T}=300^{\circ} \mathrm{K}$ )

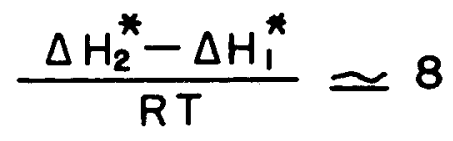

(X)

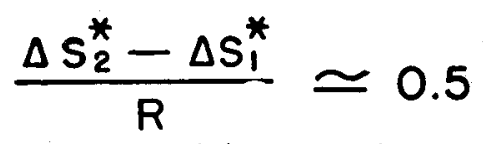

Here the change in $\Delta S^{*}$, while not 0 , is too small to effect the value of $\sigma \rho$ within the limits of error, generally in the neighborhood $\pm 10 \%$. It is this type of behavior which allows the Hammett equation to be fit to a series of reactions in which $\Delta S^{*}$ is essentially constant. If the restriction of constancy of $\Delta S^{*}$ were absolute very few reactions could be correlated by means of equation (I). Hammett (5) generally allows $\Delta S *$ to vary at least 0.2 e.u. and frequently more if the change in enthalpies of activation is sufficiently large.

\section{Reactions in which}

(XI)

$$
\frac{\Delta S_{2}^{*}-\Delta S_{1}^{*}}{R}=\text { constant } \times \frac{\Delta H_{2}^{*}-\Delta H_{1}^{*}}{R T}
$$

Such reactions have been reported in the literature (8) (9) (10) (11). The graph of the data of Blomquist and Bernstein Fig. 1 gives a very good straight line plot of $\Delta S^{*}$ vs $\Delta H^{*}$.

Table I. Data of Blomquist and Bernstein (10) on the thermal decomposition of p-substituted t-butyl perbenzoates in phenyl ether.

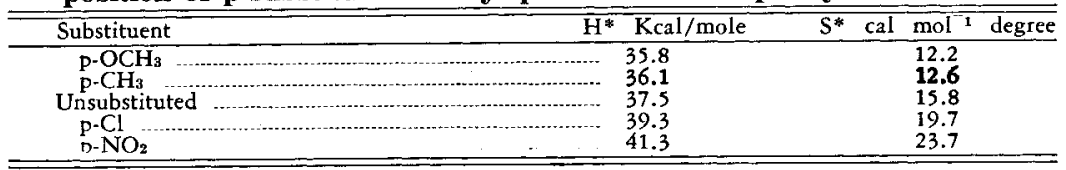




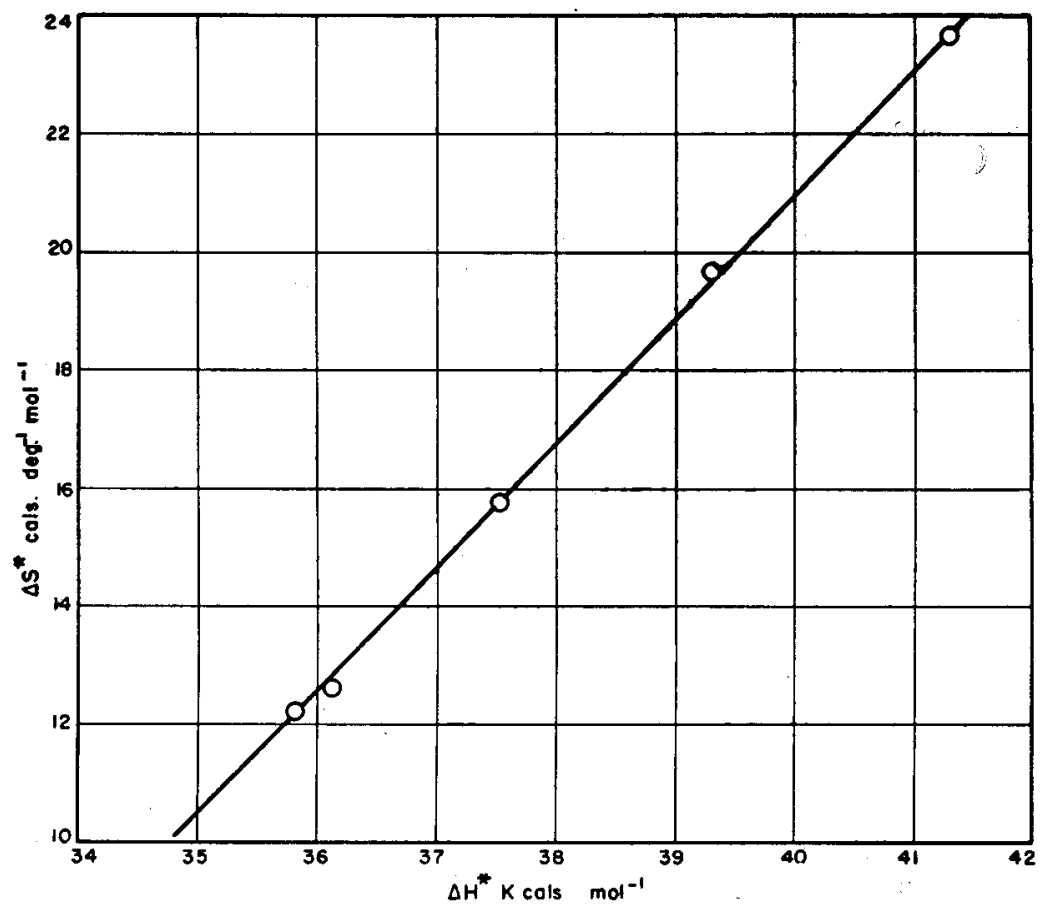

Fig. 1

The data of many other references have been given in terms of collision theory. These data, however, may be used to calculate $\Delta S^{*}$ by means of the relation: (12)

(XII)

$$
k_{\text {soln }}=e^{\frac{K T}{h}} e^{-\frac{E \text { exp. }}{R T}} \cdot e^{\frac{\Delta S^{*}}{P}}
$$

(XIII)

$$
\text { E exp. }
$$

also $k_{\text {soln }}=z e^{-\overline{R T}}$

(XIV)

$$
\text { so } z=e^{\frac{K T}{h}} e^{\frac{\Delta S^{*}}{R}}
$$

$$
\begin{aligned}
& \log z=\log 16.3 \times 10^{12}+\frac{\Delta S^{*}}{R} \\
& (X V I) \quad \Delta S^{*}=2.3 R(\log Z-13.222)
\end{aligned}
$$


Table II. Data of Branch and Nixon. The Rates of Alcoholysis of Acyl Chiorides.

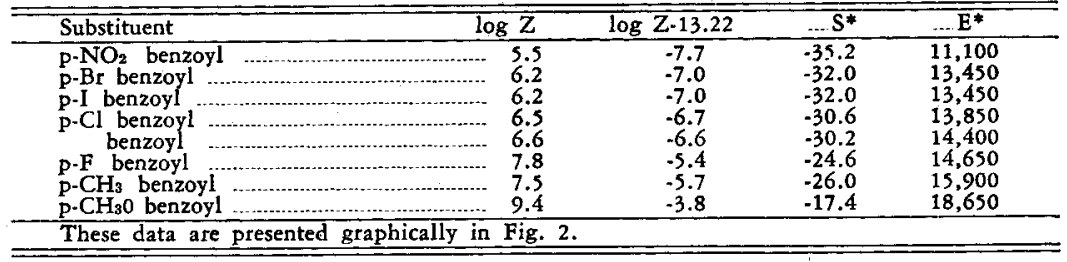

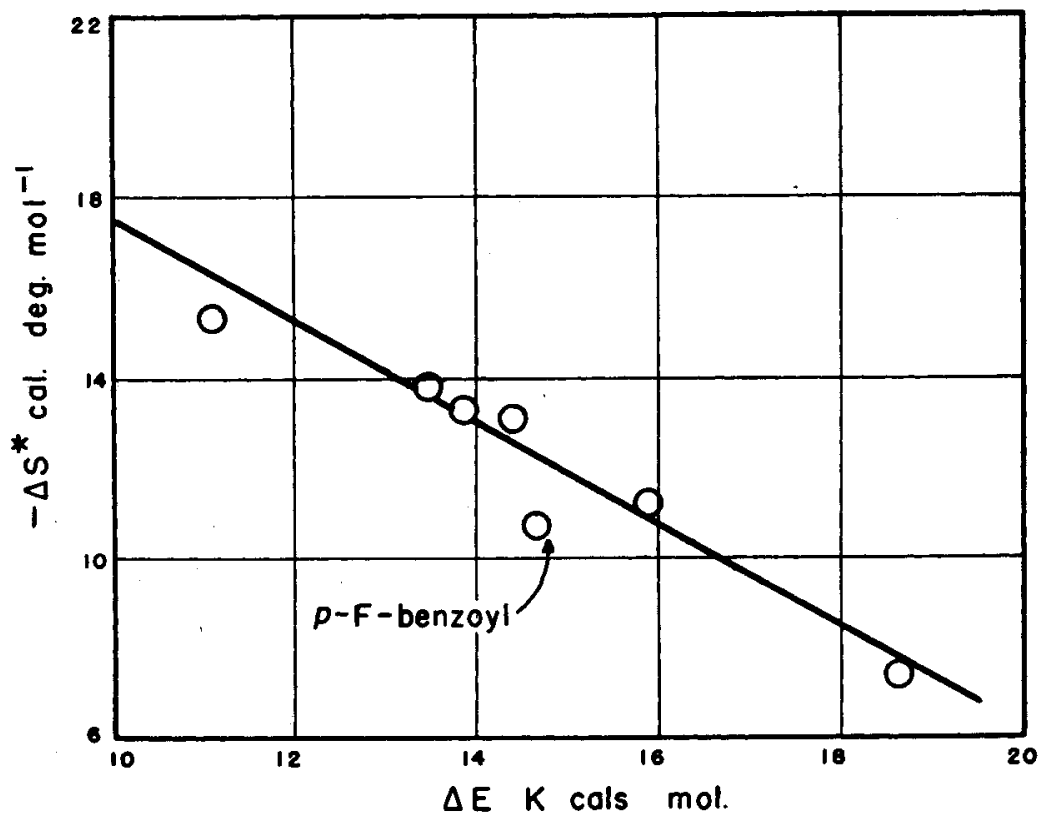

Fig. 2

The data of Timm and Hinshelwood (8) were plotted as $\log Z$ vs $\Delta \mathrm{E}^{*}$ by the authors of that paper and a linear relationship was found. This behavior is equivalent to a linear relationship between $\Delta \mathrm{S}^{*}$ and $\Delta \mathrm{E}^{*}$. The data of Davis (9) and of Burkhardt et. al. (6) also show a similar trend of $\Delta \mathrm{S}^{*}$ with $\Delta \mathrm{E}^{*}$. The data of Cristol et. al. do not possess the same regularity but their overall deviation is quite large. These facts emphasize the point that the Hammett equation is primarily a linear free energy relationship. If both $\Delta H^{*}$ and $\Delta S^{*}$ are representable as linear functions of some property of the substituents, $\Delta \mathrm{F}^{*}$ will also be. This raises the question "Can the $\sigma$ constants still be given the same interpretation as in reactions where $\Delta S^{*}$ is a constant?" The answer to this question will depend upon the particular reaction studied, but when the 
$\sigma$ constants used are the same as when $\Delta S^{*}$ is constant it seems reasonable to retain their original interpretation. When this is done, however, we should be wary about using such reactions to distinguish between the electrical effects of substituents with nearly equal $\sigma$ values.

\section{Summary}

The usefulness of the Hammett equation in some unexpected instances is explained on the basis of the Absolute Reaction Rate Theory. Caution is recommended in the use of such reactions in theoretical studies of substituent effects.

\section{Bibliography}

(1) Hammett, L. P., and Pfluger, H. L., J. Am. Chem. Soc. 55, 4079 (1933).

(2) Hammett, L. P., Chem. Revs. 17, 125 (1935).

(3) Hammett, L. P., J. Am. Chem. Soc. 59, 96 (1937).

(4) HammetT, L. P., Trans. Farad. Soc. 34, 156 (1937).

(5) Hammett, L. P., "Physical Organic Chemistry" p. 118, New York (1940).

(6) Burkhardt, G. N., Horrex, C., and Jenkins, D. S., J. Chem. Soc. 1649 (1936).

(7) Branch, G. E. K., and Nixon, A. C., J. Am. Chem. Soc. 58, 492 (1936).

(8) Timm, E. W., and Hinshelwood, C. N., J. Chem. Soc. 862 (1938).

(9) Davis, W. C., J. Chem. Soc. 1865 (1938).

(10) Blomquist, A. T., and Bernstein, I. A., J. Am. Chem. Soc. 73, 5546 (1951).

(11) Cristol, S. J., et alii., J. Am. Chem. Soc. 74, 3333 (1952).

(12) Glasstone, S., Laidler, K. J., and EYring, H., "The Theory of Rate Processes" p. 199, New York (1941). 